Wayne State University

DigitalCommons@WayneState

Library Scholarly Publications

Wayne State University Libraries

$1-1-2008$

\title{
MedlinePlus Go Local: The librarian's tool for promoting hospital services to the community
}

Annette M. Healy

WayneState University, amhealy@wayne.edu

\section{Recommended Citation}

Healy, Annette M., "MedlinePlus Go Local: The librarian's tool for promoting hospital services to the community" (2008). Library Scholarly Publications. Paper 34.

http://digitalcommons.wayne.edu/libsp/34

This Article is brought to you for free and open access by the Wayne State University Libraries at DigitalCommons@WayneState. It has been accepted for inclusion in Library Scholarly Publications by an authorized administrator of DigitalCommons@WayneState. 


\title{
MedlinePlus Go Local: The librarian's tool for promoting hospital services to the community
}

\section{Annette M. Healy}

\begin{abstract}
Healthcare systems are complex organizations that patients and families may find difficult to navigate. MedlinePlus Go Local projects are assisting consumers in this navigation by developing directories of health services that are indexed by geographic area, types of services provided and associated health issues. Librarians affiliated with healthcare systems can play a critical role in promoting their organization and assisting healthcare consumers in locating needed services by assisting Go Local projects in accurately indexing their organization and assisting with keeping the information up-to-date.
\end{abstract}

Key words: MedlinePlus, Go Local, hospital libraries, marketing

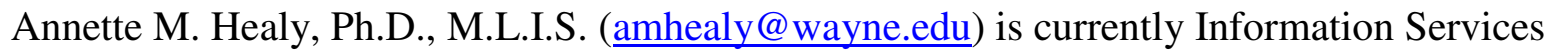
Librarian at the Science \& Engineering Library, Wayne State University, Detroit, MI 48202 and previously served as Information Services Librarian at Shiffman Medical Library, Wayne State University and Project Director of Michigan Go Local. 
Consumers are increasingly turning to the Internet for health information. According to the Pew Internet \& American Life Project, 10 million American adults look online for health information on a typical day. ${ }^{1}$ Many websites, including those sponsored by government, professional and non-profit organizations provide access to quality health information. However it is much more difficult to locate information about services provided by health organizations. This type of information may be located in print directories not readily available to the public, in scattered locations on the Internet, or buried in the websites of health organizations. Go Local projects, being developed in partnership with the National Library of Medicine (NLM), each provide a searchable electronic resource listing of health services located in a given region. These projects, freely accessible to all users, will greatly assist consumers, librarians and health referral providers in locating a wide range of health services. In addition, Go Local projects benefit health organizations by increasing the visibility of the many health services and programs they offer. Thus, hospital librarians can provide added value to their organizations by insuring that the information about their organization included in their local Go Local project is accurate and complete.

\section{What is MedlinePlus Go Local?}

MedlinePlus Go Local <http://www.nlm.nih.gov/medlineplus/golocal/> is an initiative by the National Library of Medicine to develop online directories of health services. All Go Local projects are linked to MedlinePlus <http://medlineplus.gov/>, the gateway to high quality consumer health information developed and maintained by the National Library of Medicine. MedlinePlus is the most heavily used government-sponsored site for consumer health information. ${ }^{2}$ In the fourth quarter of 2006, 28.3 million unique visitors viewed 220 million pages of MedlinePlus. ${ }^{3}$ The goal of MedlinePlus is to provide links to quality information about 
diseases and health issues. NLM acknowledged the need for directories of local health service information but also recognized that local organizations would be better equipped to provide information about services in their region. ${ }^{2}$ With this in mind, NLM has partnered with state and local organizations interested in developing Go Local projects in their region. At this writing, there are 21 Go Local projects online and several others under development. Go Local projects develop databases of health services, programs and providers that are indexed by geographic service area, types of services provided and associated health issues. Go Local sites can be accessed in several ways including directly visiting the site, referral from MedlinePlus or referral from another website that provides a link. A visitor to MedlinePlus can access information about a particular health topic such as fibromyalgia and then be linked to Go Local to find health services for fibromyalgia in their community. Because millions of users visit MedlinePlus every month, the links to the Go Local projects will provide increased visibility to the health organizations in their databases. Users that begin at the Go Local site serving their community to locate health services for fibromyalgia, for example, will also find links to MedlinePlus for health information on fibromyalgia. Thus, a user can easily move between MedlinePlus for health information and Go Local to locate health services.

\section{How are Go Local projects developed?}

Libraries and other organizations interested in developing a Go Local project in their region can submit a written proposal to NLM as described in the MedlinePlus Go Local Participation Guidelines. ${ }^{4}$ Projects can choose to use the NLM-based Go Local system or to use a locally-supported system. The NLM Go Local system provides the hardware, software, and vocabulary required for the project and greatly reduces the resources and expertise needed for the project. Hilligoss and Silbajoris ${ }^{5}$ have described the development of the first Go Local project, 
NC Health Info, which uses a locally supported database system. Based on the NC Health Info experience, NLM developed a database system that could be used by projects that do not have the resources and expertise to develop and support their own system. The NLM-based system is housed on servers at the National Library of Medicine and includes easy-to-use web-based forms for data entry, editing and maintenance. The development of Go Local projects in Indiana and Massachusetts, which employ the NLM-hosted system, have recently been described. ${ }^{6-7}$ The rest of this article will focus on projects using the NLM-hosted system.

Major responsibilities of a Go Local project include building and maintaining the database and outreach and promotion. Building the database requires the creation of records for health services, programs and providers that serve consumers in their region. Each project establishes selection guidelines that help identify appropriate organizations for the database. Data may be entered manually into the web-based data input form that NLM has created or by importing data from an existing database. Each record must then be indexed by geographic service area using the zip code, the counties served, or the entire region as the service area. Each record is also indexed by health services provided. There are more than 160 different health service terms and as many terms as necessary can be used to describe the services provided by a given organization or program. Health service terms include providers such as Allergists and Genetic Counselors, facilities such as Hospitals and Clinics, and services such as Support Groups and Health Education Programs. To more precisely define the scope of the health service, each health service term is then mapped to one or more health topics. For example, a breast cancer support group would be indexed as Support Groups, Breast Cancer and a diabetes education program would be indexed as Health Education Program, Diabetes. There are approximately 300 health topics to choose from, and these topics are a subset of the more than 
700 MedlinePlus health topics. MedlinePlus health topics not included in the Go Local vocabulary are assigned to a broader MedlinePlus health topic. For example, the term Aneurysms is assigned to the broader topic Vascular Diseases. The use of MedlinePlus health topics allows the user to move seamlessly from Go Local services for a particular health topic to medical information on that health topic from MedlinePlus and vice versa.

An important element for the success of Go Local projects is the currency and accuracy of the information in the databases. NLM provides weekly reports of broken links to assist projects in keeping the URLs in the database current. Identified broken links can then be updated or turned off by project staff so that users encounter as few broken links as possible. Each project also establishes and implements a plan for reviewing and updating each record in the database, usually annually or semiannually. Records are reviewed on a regular basis to determine that the information in the record such as address, phone number, URL, and services provided is accurate. In addition, organizations can use a Contact Us form on the Go Local site to update their information or have their organization added to the database.

Each Go Local project also implements outreach and promotional activities to inform their constituencies about the project. Each project can establish the activities that best meet the needs of their region. Promotional activities that have been used successfully include public service announcements, radio advertisements, exhibits at health fairs and conferences, press releases, announcements on discussion lists and distribution of promotional items. ${ }^{6-7}$ To help monitor usage of Go Local sites, NLM provides each Go Local project with monthly usage statistics that includes a wide variety of data including the number of visits from particular cities and the number of visits referred from a particular site or domain. This data assists Go Local 
projects in monitoring the usage of the site and can be used to target promotional activities on regions where usage is at a low level.

\section{Increased Visibility for Programs and Services}

Today's health systems and hospitals are complex organizations that can be difficult to navigate for the average patient or family member. In addition, health systems may encounter barriers when promoting community awareness of the wide variety of health programs and services they provide. Go Local projects can bridge this gap by indexing the many programs and services offered by a health system. Because Go Local projects are linked to MedlinePlus, the popular consumer health website from NLM, increased visibility of programs and services included in Go Local projects will result. Public libraries and other local organizations may also provide links to a Go Local project and increase its visibility. Shortly after launch in January 2007, a link to Michigan Go Local was added to Michigan eLibrary <http://www.mel.org>, an electronic library developed and maintained by the Library of Michigan. Several public libraries in Michigan have also included Michigan Go Local on their websites.

For Go Local projects, hospitals and health systems present difficult challenges for creating and indexing records because of the complexity of the organizations. These organizations include a variety of facilities, services and programs that cannot be accurately described in a single record. INHealthConnect created records for each hospital service that had its own unique URL. ${ }^{7}$ Michigan Go Local created separate records for numerous programs and services offered by hospitals and health systems in the state. Separate records were created for the many facilities, services and programs listed on an organization's website, including clinics, laboratory testing facilities, diagnostic imaging facilities, and rehabilitation programs, as well as health education programs, fitness programs and support groups. If organizations identify 
programs that are not included in the Go Local database serving their area, they can contact the Go Local project to request that a program be added. A contact form on each Go Local site facilitates contact with project staff. Thus, participating in a Go Local projects presents an opportunity for hospital librarians to provide significant added value to their organization by assisting their local Go Local project in keeping their organization's records complete and up-todate.

The Go Local vocabulary used to index programs and services provides a powerful tool for locating specific services that may be difficult to locate using a health system website, print directory or word of mouth. The Go Local vocabulary includes more than 160 terms to describe the types of services a program or organization offers. These terms include common terms such as Clinic, Hospital and Family Physician as well as more specific terms such as Bilingual Services, Infusion Therapy Services and Patient/Family Housing. Each of these terms is associated with health topics that narrow the scope of the term as well as provide additional opportunities for users to locate a desired service. The NLM-based system provides users with several methods, indicated by arrows in Figure 1, for locating health services.

\section{INSERT FIGURE 1}

First, users can begin by choosing a geographic location such as a zip code, county or city, and then choose services of interest in that region. Second, users can choose a type of provider, facility or service such as Allergist, Nursing Home or Support Group and then narrow their search geographically. Third, users can choose a disease or health issue such as Diabetes, narrow their search geographically, and then identify the type of service they need such as Endocrinologist or Health Education Program. Figure 2 illustrates the wide range of diabetes services available in Wayne County, Michigan. 


\section{INSERT FIGURE 2}

NLM also provides numerous "see" references in the lists of service terms and health topics to assist users in their search. Thus, the extensive indexing of health services and health topics combined with the intuitive interface allows users to easily locate health services and programs offered by a health system or hospital.

There are many services that hospitals and health systems offer that may be difficult for community members to locate. Some of these services that are included in the Go Local vocabulary include Bilingual Services, Support Groups, Health Education Programs, Health Screening Programs, Fitness Programs and Library. Complementary and alternative medicine programs are becoming increasingly popular and Go Local includes terminology for Acupuncturists, Massage Therapists, Meditation Programs and Yoga Programs among others to help users locate these services. Each of these services can be mapped to the health topic Alternative Medicine to further facilitate their identification by users. In addition, NLM encourages suggestions from Go Local projects for new service terms. Once a new term is suggested, Go Local projects are surveyed about the need for the term and NLM creates appropriate vocabulary based on the input they receive. Thus, the NLM-based system and the affiliated Go Local projects will be able to adapt to changes in healthcare services and terminology in the future. The broad range of service terms and health topics available in the Go Local vocabulary can provide increased visibility for the many services and programs offered by hospitals and health systems. Librarians affiliated with these institutions can play a significant role in promoting their organization by assisting Go Local project staff in collecting information about the services provided by their institution and contributing to the accurate indexing of these services. 


\section{References}

1. Fox S. Online health search 2006. [Web document] Washington DC: Pew Internet \& American Life Project, October 29, 2006. [Cited February 16, 2007]. Available from: http://www.pewinternet.org/pdfs/PIP_Online_Health_2006.pdf

2. Miller N. The NLM-hosted Go Local system: An opportunity for medical libraries. [Web document]. U.S. National Library of Medicine, 2006: [Cited February 16, 2007]. Available from: http://www.nlm.nih.gov/medlineplus/golocaldocs/nlmhostedsystem.pdf

3. U.S. National Library of Medicine. MedlinePlus statistics [Web document] Bethesda, MD: U.S. National Library of Medicine, January 31, 2007 [Cited February 16, 2007]. Available from: http://www.nlm.nih.gov/medlineplus/usestatistics.html

4. U.S. National Library of Medicine. MedlinePlus Go Local participation guidelines. [Web document]. U.S. National Library of Medicine, December 2006. [Cited February 16, 2007]. Available from http://www.nlm.nih.gov/medlineplus/golocaldocs/Go_Local_Participation-rev-4$\underline{06 . d o c}$

5. Hilligoss B, Silbajoris C. MedlinePlus goes local in NC: The development and implementation of NC Health Info. Journal of Consumer Health on the Internet 2004; 8(4):9-26.

6. Gore S. All health is local: Go Local Massachusetts helps consumers locate health care services close to home. Journal of Consumer Health on the Internet 2006; 10(4):1-14.

7. Richwine P, Skopelja E, Rider L. Better than the yellow pages: Go Local for health services where you live. Journal of Consumer Health on the Internet 2006; 10(4):15-26. 